\title{
EVALUATION OF THE LONG-TERM MECHANICAL BEHAVIOR IN THE NEAR-FIELDS CONSIDERING CHEMICAL TRANSITIONS OF BARRIER MATERIALS
}

\author{
Fumihiro Sahara \\ KAJIMA Corporation \\ saharaf@kajima.com \\ Morihiro Mihara \\ Japan Atomic Energy Agency \\ mihara.morihiro@jaea.go.jp
}

\author{
Takeshi Murakami \\ KAJIMA Corporation \\ takeshi-murakam@kajima.com \\ Takao Ohi \\ Japan Atomic Energy Agency \\ ohi.takao@jaea.go.jp
}

\section{INTRODUCTION}

According to the current radioactive waste disposal concept in Japan, TRU wastes are being considered for emplacement in large underground cavities utilizing cementitious filler and structural members and bentonite materials as buffer. These engineered barriers, in the long term, may be altered chemically by the reaction between cement and bentonite, which leads to a change in hydraulic characteristics and mechanical properties.

In order to make a reliable evaluation of the performance of TRU waste repository, MACBECE was developed (Sahara, et al., 2006). MACBECE is the system that calculates the deformation and the hydraulic conductivity of barrier materials using their chemical property changes as inputs. By using MACBECE, the long-term deformation and the transition of hydraulic field for the round-type disposal cavities were evaluated, assuming some sets of chemical evolution data as input.

\section{EVALUATION OF LONG-TERM MECHANICAL STABILITY}

Assuming 4 different chemical alteration scenarios with hard rock and soft creeping rock, a series of analytical case studies was performed. The analysis model is shown in Fig.1. For cases of hard rock, the rock creep is negligible. Meanwhile, for cases of soft host rock, it is not negligible and the creep deformation of the host rock is used as boundary condition. The deformation is calculated by a conventional methodology (JAEA and FEPC, 2007).

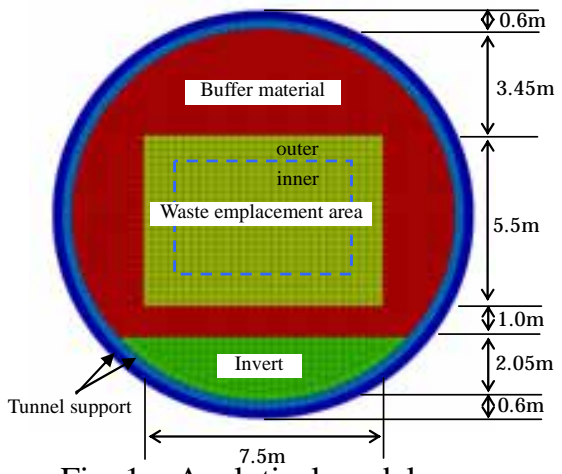

Fig. 1 Analytical model
The displacements in the final stage of case (iii) are shown in Fig.2. It was assumed in the case that $25 \%$ of original amount of calcium was leached in outer of waste emplacement area and 50\% of smectite in bentonite buffer was altered to non-swelling minerals. They indicate that, in the case of hard rock, the displacement inside the tunnel is very small, and in the case of soft rock, it depends strongly on the rock creep displacement.

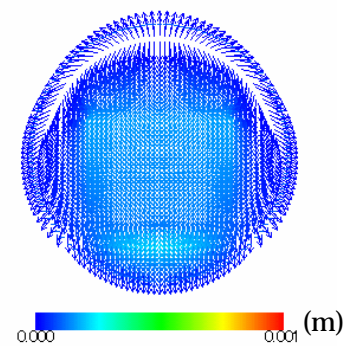

(a) hard rock

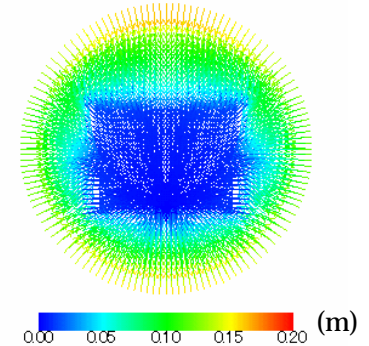

(b) soft rock
Fig. 2 Deformation contours of Case (iii)

(The color and arrow correspond to the displacement and the direction.)

\section{CONCLUSIONS}

The long-term deformation of the saturated engineered barrier is analyzed by using MACBECE.

In hard rock cases, tunnel deformation by swelling pressure of the buffer material is insignificant and the buffer material seems to remain intact. On the other hand, for the cases with creeping host rock, buffer material is compacted to some extent. Nevertheless, since the analysis condition was set conservatively and the density of the buffer increases due to compaction (i.e., the permeability decreases), it can be considered that the influence on the nuclide migration is insignificant.

\section{REFERENCES}

Sahara, F., et al., 2006, "Development of a Mechanical Analysis System Considering Chemical Transitions of Barrier Materials", WM'06, Tucson, Arizona

JAEA and FEPC, 2007, "Second Progress Report on Research and Development for TRU Waste Disposal in Japan -Repository Design, Safety Assessment and Means of Implementation in the Generic Phase-“, (in preparation) 


\section{EVALUATION OF THE LONG-TERM MECHANICAL BEHAVIOR IN THE NEAR-FIELDS \\ CONSIDERING CHEMICAL TRANSITIONS OF BARRIER MATERIALS}

\author{
Fumihiro Sahara \\ KAJIMA Corporation \\ 6-5-30, Akasaka, Minato-Ku, Tokyo, Japan \\ Phone:+81-3-6229-6697, Fax:+81-3-5561-2152 \\ saharaf@kajima.com
}

\author{
Morihiro Mihara \\ Japan Atomic Energy Agency \\ 4-33, Muramatsu, Tokai-mura, Naka-gun, \\ Ibaraki-ken, Japan \\ Phone:+81-29-282-1111, Fax:+81-29-282-9328 \\ mihara.morihiro@jaea.go.jp
}

\author{
Takeshi Murakami \\ KAJIMA Corporation
}

6-5-30, Akasaka, Minato-Ku, Tokyo, Japan

Phone:+81-3-6229-6796, Fax:+81-3-5561-2153

takeshi-murakam@kajima.com

Takao Ohi
Japan Atomic Energy Agency
4-33, Muramatsu, Tokai-mura, Naka-gun,
Ibaraki-ken, Japan
Phone:+81-29-282-1111, Fax:+81-29-282-9328
ohi.takao@jaea.go.jp

Keywords: MACBECE, transitions, TRU waste disposal, deformation, hydraulic field

\begin{abstract}
An analysis system for the long-term mechanical behavior of barrier materials (MACBECE: Mechanical Analysis system considering Chemical transitions of BEntonite-based and CEment-based materials) was developed in order to improve the reliability of the evaluation of the hydraulic field which is one of the important environmental conditions in the safety assessment of the TRU waste disposal. MACBECE is the system that calculates the deformation of barrier materials using their chemical property changes as inputs, and subsequently calculates their hydraulic conductivity taking both their chemical property changes and deformation into consideration.

By using MACBECE, the long-term deformation and the transition of hydraulic field for the round-type disposal cavities were evaluated, assuming some sets of chemical evolution data as input. Based on the analysis result, it is considered that the influence of the long-term deformation of the barrier materials on the nuclide migration is not necessarily significant.
\end{abstract}

\section{INTRODUCTION}

According to the current radioactive waste disposal concept in Japan, TRU wastes, (low level radioactive wastes that include long-lived nuclides), are being considered for emplacement in large underground cavities utilizing cementitious filler and structural members and bentonite materials as buffer. The safety assessment for this disposal concept indicates that I-129 and C-14 which are soluble and non-sorptive are the key nuclides that have significant radiological impact on biosphere. And it is considered that the groundwater flow has significant effect on migration of these nuclides.

Engineered barriers of the TRU waste repository, in the long term, may be altered chemically by the reaction between cement and bentonite, which leads to a change in hydraulic characteristics and mechanical properties.

It is observed that calcium ions may leach out of cement-based materials, which increase the hydraulic conductivity of the cement and also change its mechanical properties such as rigidity and strength.

Also it seems plausible that calcium ions supplied from cement-based materials may cause Na-bentonite to alter to Ca-bentonite, which increases permeability and changes the bentonite mechanical properties such as swelling. Consequently the change in the mechanical properties may cause the deformation of the barrier materials that could 
result in change in permeability.

Thus, in order to achieve a more reliable safety assessment, it will be necessary to develop the system that can evaluate long-term transition of hydraulic field of the near-field with taking into account the changes in the barrier material properties. MACBECE (Sahara, et al., 2006), which was developed with this view, is expected to serve as a key element of the evaluation system (see Fig.1).

And the analysis shown below was conducted for issuing "Second Progress Report on Research and Development for TRU Waste Disposal in Japan” (the Federation of Electric Power Companies of Japan (FEPC) and Japan Atomic Energy Agency (JAEA), 2007), which is hereafter referred to as "TRU-2".

\section{DESCRIPTION OF MACBECE \\ 2.1 Analysis Flow}

Left-hand side (green area) of Fig.1 shows the flow diagram of MACBECE that is a FEM based long-term mechanical behavior analysis system (Sahara, et al., 2006).

In MACBECE, initial conditions are set as those after a disposal tunnel is re-saturated and then the initial stress field is calculated using self weight, initial properties of each barriers, swelling pressure of the bentonite-based materials, and etc.

Change of the mechanical properties of each barrier material and operating forces due to additional deformation of the materials, are calculated based on the input indices which represent chemical transition in the materials (hereafter referred to as chemical transition indices). The deformation and the stress state at a time step are obtained by solving the balance of operating forces considering the mechanical property changes. Distribution of hydraulic conductivity is calculated based on the chemical property changes as well as the obtained deformation.

Although not described in Fig.1, the effect of rock creep deformation around a disposal tunnel can also be roughly evaluated by giving a forced displacement as boundary condition.

\subsection{Chemical Transitions of Barrier Materials}

The long-term chemical transition of bentonite-based material considered in MACBECE includes cation exchange, dissolution of smectite and formation of secondary minerals, and change in the pore water chemistry. These transitions are considered to have high possibility of occurrence and to influence on the mechanical/hydraulic properties of bentonite-based materials, according to experiments or analyses in the past (e.g. Metcalf, 2004).

On the other hand, the long-term chemical transition of cement-based material considered in MACBECE includes the leaching of $\mathrm{Ca}$ ions and formation of secondary minerals. These transitions are phenomena considered to have high possibility of occurrence based on the mineralogical analysis of old concrete structures (Yokozeki, et al., 2002a), experiments and analyses (Yokozeki, et al., 2002b).

The indices representing these chemical property changes used in MACBECE are shown in Table 1.

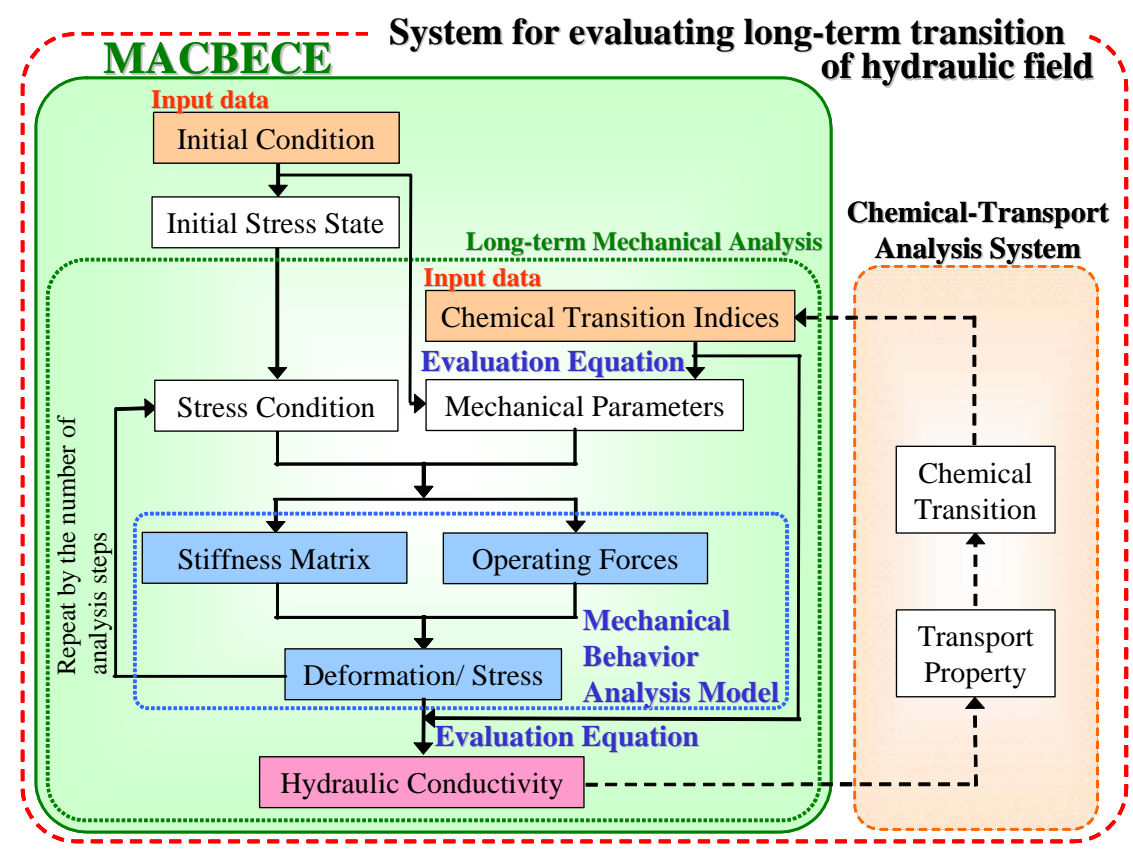

Fig.1 Flow diagram of MACBECE

Table 1 Chemical Transition Indices

\begin{tabular}{|l|l|l|}
\hline \multirow{5}{*}{ Barrier materials } & Chemical transition phenomena & Chemical transition indices \\
\hline \hline \multirow{3}{*}{$\begin{array}{l}\text { Bentonite-based } \\
\text { materials }\end{array}$} & Cation exchange & Exchangeable sodium percentage: $E S P$ \\
\cline { 2 - 3 } & Dissolution of smectite & $\begin{array}{l}\text { Smectite partial dry density: } \rho_{\text {sme }}\left[\mathrm{Mg} / \mathrm{m}^{3}\right] \\
\text { Smectite void ratio: } e_{\text {sme }} \\
\text { Porosity: } \theta_{b}\end{array}$ \\
\cline { 2 - 3 } $\begin{array}{l}\text { Cement-based } \\
\text { materials }\end{array}$ & Change in porewater chemistry & Equivalent ionic concentration: $C_{i}\left[\mathrm{eq} / \mathrm{dm}^{3}\right]$ \\
\cline { 2 - 3 } & Feaching of Ca & Peached Ca percentage: $L_{C}$ \\
\cline { 2 - 3 }
\end{tabular}




\subsection{Mechanical Behavior Analysis Model}

Bentonite-based materials are considered to deform according to the stress balance with other barrier materials while exerting its characteristic nature of swelling property. The model used in this system is an extended version of the elasto-(visco)plastic constitutive equation by Sekiguchi and Ota (1977) which was coded as a constitutive equation for natural sedimentary clay, and has been applied widely and verified. In the extended model in MACBECE, the swelling index $\kappa$, which corresponds to the tangent gradient of the swelling curve (see Fig.2(a)) of the bentonite, is shown as follows (Eq.1).

$1<O C R<O C R_{b} \quad: \kappa=\kappa_{0}+\xi \cdot O C R \cdot \exp \{\xi(O C R-1)\}$

$O C R_{b} \leq O C R \quad: \kappa=\kappa_{0}+\xi \cdot O C R_{b} \cdot \exp \left\{\xi\left(O C R_{b}-1\right)\right\} \quad$ (Eq.1)

Where, OCR $\left(=P_{0}^{\prime} / P^{\prime}\right)$ is the over-consolidation ratio, $\xi$ and $O C R_{b}$ are material constants (hereafter referred to as osmotic swelling parameters), $\kappa_{0}$ is the initial swelling index. $\xi, O C R_{b}, \kappa_{0}$ can be obtained from swelling characteristics of the materials. Key mechanical parameters required for the mechanical analysis are determined based on laboratory tests.

Cement-based material (i.e., mortar or concrete) is considered to deform by the swelling pressure of buffer material or by rock pressure while reducing its rigidity and strength according to the progress of calcium leaching (see Fig.2(b)). To express this behavior that seems similar to the strain softening behavior, a nonlinear elasticity model (e.g. Motojima, 1981) was incorporated to MACBECE. The incorporated model uses an incremental analysis technique which has good consistency with the constitutive equation and the model for bentonite behavior. Mohr-Coulomb's failure criterion and an iterative calculation method for stress redistribution are applied for strain softening behavior, which is due to reduction of the strength and the rigidity associated with the chemical deterioration.

\subsection{Hydraulic Conductivity Evaluation Model}

For bentonite-based materials, the evaluation model proposed by Ito (2005), which is based on the data from permeability test and is expressed in terms of exchangeable sodium percentage $(E S P)$, smectite void ratio $\left(e_{\text {sme }}\right)$, and equivalent ionic concentration $\left(C_{i}\right)$, was adopted for the evaluation of the hydraulic conductivity. In MACBECE, the change of the $e_{\text {sme }}$ due to deformation was also taken into account (Sahara, et al., 2006).

For cement-based materials, a proposed relation between the porosity and the hydraulic conductivity (Mihara, 2003) based on cement paste experiments data is basically applied. In defining the hydraulic conductivity-porosity relation for cement-based materials such as mortar or concrete in which aggregate as well as cement paste are contained, the porosity was converted to that of cement paste itself by deducting the aggregate' volume, and the porosity change due to deformation was also taken into consideration (Sahara, et al., 2006).

\section{EVALUATION OF LONG-TERM MECHANICAL STABILITY 3.1 Introduction}

This section describes the evaluation of long-term mechanical stability in the near-field after closure of the disposal tunnels. In particular, it is intended to make sure if or not the assumed thickness of the buffer material (i.e., $1.0 \mathrm{~m}$ ) in the nuclide migration analysis in "TRU-2", are maintained in the long term. As previously described, this evaluation was conducted for issuing "TRU-2" (JAEA and FEPC, 2007).

\subsection{Analytical conditions}

The analysis model is shown in Fig.3 and the modeling concept of the engineered barrier system is shown in Table 2 (JAEA and FEPC, 2007).

Evaluation target is a round-type disposal tunnel in soft rock with internal diameter of $12.0 \mathrm{~m}$ (excavated diameter $13.2 \mathrm{~m}$ ). Two-dimensional analytical model is created based on the designed tunnel cross-section and the initial waste emplacement location in the analysis model is set $0.2 \mathrm{~m}$ lower than that specified in design (the thickness of the buffer material under the waste emplacement area is designed as $1.2 \mathrm{~m}$.) in order to take into account the assumed rapid subsidence due to the weight of the waste.

The long-term deformation behavior is calculated based on multi-step analysis approach. At each analysis step, incremental deformation is calculated using chemical transition indices (properties) as inputs and the corresponding mechanical properties.

With regard to the spatial distribution of the chemical property on which the above calculation is based, although

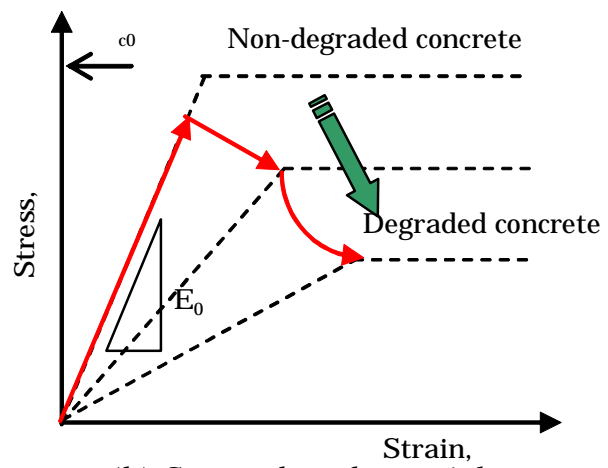

(b) Cement-based materials

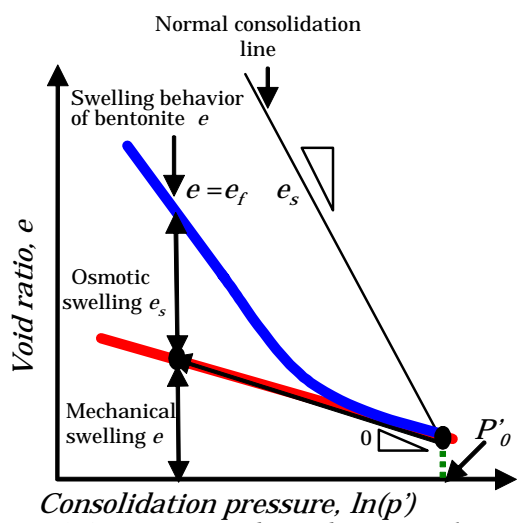

(a) Bentonite-based materials

Fig.2 Concept of mechanical behavior analysis model 
an analysis indicates that sufficient amount of montmorillonite remains after 100,000 years and Na-montmorillonite is dominant for several 10,000 years, concerns about the longevity of montmorillonite, i.e., the possibility that the alteration occurs much earlier (e.g., after several thousand years), cannot be ruled out. In this study, aiming to examine the degree of influence of each factor/process controlling the deformation, 4 cases (i-iv) are set to be analyzed (see Table 3).

The rate of chemical evolution is assumed to be constant over analysis time span. Two types of host rock behavior were assumed for the analysis: (a) the cases where the rock creep is negligible (hard rock) and (b) the cases where rock creep is not negligible (soft rock). The creep deformation of the host rock is used as boundary condition. For cases of soft host rock, the deformation is calculated by a conventional methodology and the displacements of side and top were $11.8 \mathrm{~cm}$ and $16.2 \mathrm{~cm}$, respectively (JAEA and FEPC, 2007).

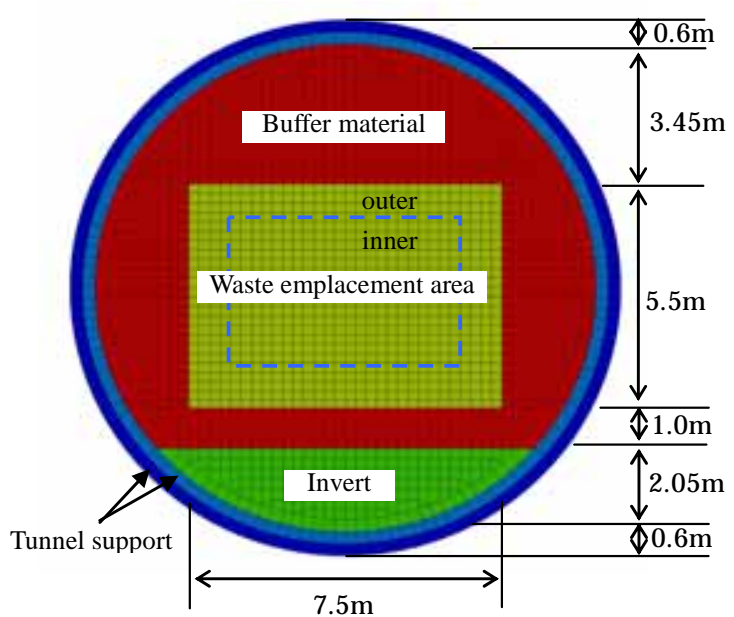

Fig.3 Analytical model

Table 2 Model of the engineered barriers

\begin{tabular}{|l|l|}
\hline EBS member & Specification for analysis \\
\hline $\begin{array}{l}\text { Emplaced waste form } \\
\text { (Waste, filling material, structural framework) }\end{array}$ & $\begin{array}{l}\text { Mortar } \\
(\mathrm{W} / \mathrm{C}=55 \% \text {, aggregate } 54 \text { vol\%) }\end{array}$ \\
\hline Buffer material & $\begin{array}{l}\text { Bentonite mixed with silica sand (dry density } 1.6 \\
\mathrm{Mg} / \mathrm{m}^{3} \text {, mixing ratio of silica sand 30 wt\%) }\end{array}$ \\
\hline Invert & $\begin{array}{l}\text { Concrete } \\
\text { Secondary lining, shotcrete }\end{array}$ \\
\hline
\end{tabular}

Table 3 Evolution of chemical properties up to final step

\begin{tabular}{|c|c|c|c|c|c|}
\hline & & & Emplaced waste & & \\
\hline & & $\begin{array}{l}\text { Center } \\
\text { (inner) }\end{array}$ & $\begin{array}{l}1 \mathrm{~m} \text { from boundary of buffer } \\
\text { (outer) }\end{array}$ & Buffer material & $\begin{array}{l}\text { Invert } \\
\text { Support }\end{array}$ \\
\hline$\therefore$ & (a) & No & $25 \%$ of original amount of & & $100 \%$ of original amount \\
\hline 1 & (b) & change & calcium is leached & dilge & of calcium is leached \\
\hline & (a) & No & $25 \%$ of original amount of & & $100 \%$ of original amount \\
\hline 11 & (b) & change & calcium is leached & owered irc & of calcium is leached \\
\hline iii & (a) & No & $25 \%$ of original amount of & Smectite partial density only is decreased from 0.92 & $100 \%$ of original amount \\
\hline III & (b) & change & calcium is leached & $\mathrm{Mg} / \mathrm{m}^{3}$ to $0.55 \mathrm{Mg} / \mathrm{m}^{3}$ & of calcium is leached \\
\hline is & (a) & No & $25 \%$ of original amount of & Equivalent ionic concentration of groundwater only & $100 \%$ of original amount \\
\hline IV & (b) & change & calcium is leached & is increased from $0 \mathrm{eq} / \mathrm{dm}^{3}$ to $1 \mathrm{eq} / \mathrm{dm}^{3}$ & of calcium is leached \\
\hline
\end{tabular}

*: In case (a), the creep effect was not considered and in case (b), the creep effect was considered.

\subsection{Analytical results}

The displacements in the final stage of case (i-a iv-a) and case (i-b iv-b) are shown in Fig.4. In the case of $\mathrm{i}-\mathrm{a} \sim \mathrm{iv}-\mathrm{a}$, displacement inside of the tunnel is no more than 1 $\mathrm{mm}$, which is because there is no rock deformation and the waste emplacement area keeps high rigidity (1,000 $\mathrm{MPa}$ even at the final strep). Also buffer material is considered not to crack/behave discontinuously in this case as no tensile stress is aroused.

In the case of $\mathrm{i}-\mathrm{b} \sim \mathrm{iv}-\mathrm{b}$, the tunnel is deformed entirely inward (towards the center) as the result of applied creep displacement with maximum of $16 \mathrm{~cm}$. Comparing the displacement of emplaced waste forms with that of buffer materials makes it clear that deformation mostly occurs in buffer material with lower elastic modulus. The minimum thickness of deformed buffer material after deformation is about $95 \mathrm{~cm}$ under the waste emplacement area.

Fig. 5 displays the alteration of hydraulic conductivity of buffer material (top graph) and cement-based materials (bottom graph) respectively for the case of iii-a and iii-b. Hydraulic conductivity displayed in the figure is the one for the point where hydraulic conductivity shows the highest value at the final step. The alteration by only chemical reaction (without deformation) is also shown for reference. In the case of iii-a in which rock creep is neglected and the deformation is relatively small, the permeability change is depending almost only to the chemical alteration. While in the case of iii-b, the permeability is reduced noticeably by compression due to creeping host rock.

It should be noted that both soft rock and hard rock cases (with/without creep), even the deformation mode and distribution of permeability are different, still remain the hydraulic conductivity of bentonite in the order of $10^{-12}$ and therefore it is considered that the buffer in both cases can keep diffusion-dominant field to prevent rapid nuclide transport. 


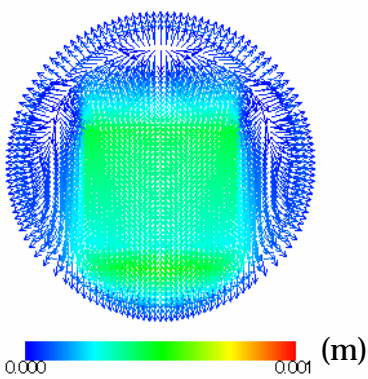

(a) Case(i-a)

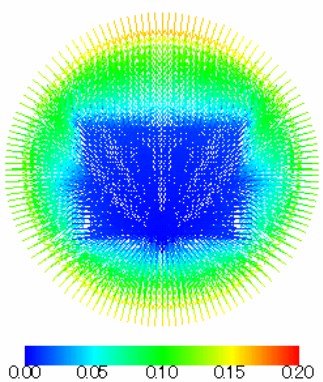

(e) Case(i-b)

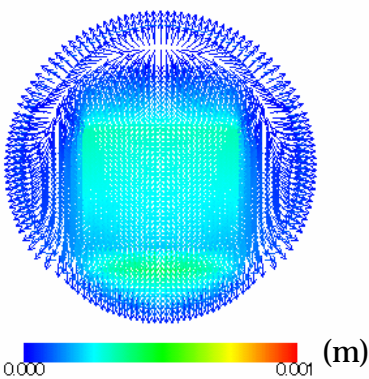

(b) Case(ii-a)

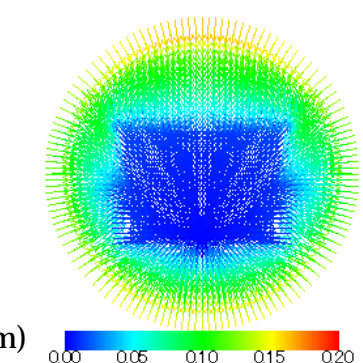

(f) Case(ii-b)

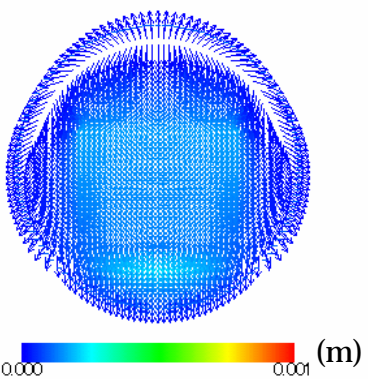

(c) Case(iii-a)

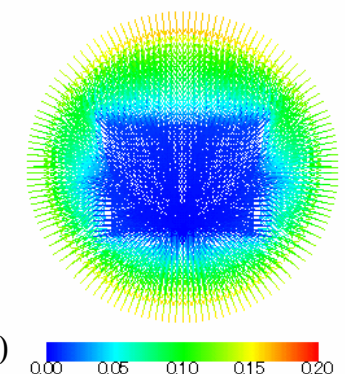

(g) Case(iii-b)

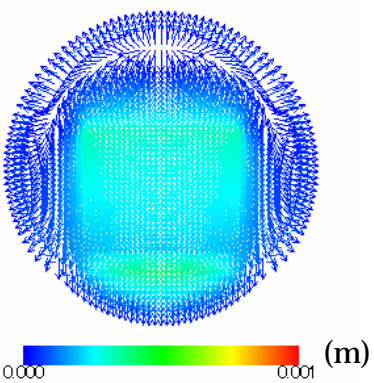

(d) Case(iv-a)

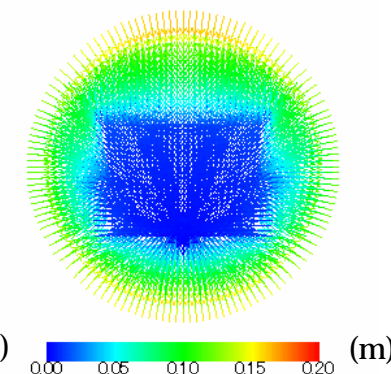

(h) Case(iv-b)

Fig.4 Deformation contours

(The color and arrow correspond to the displacement and the direction.)
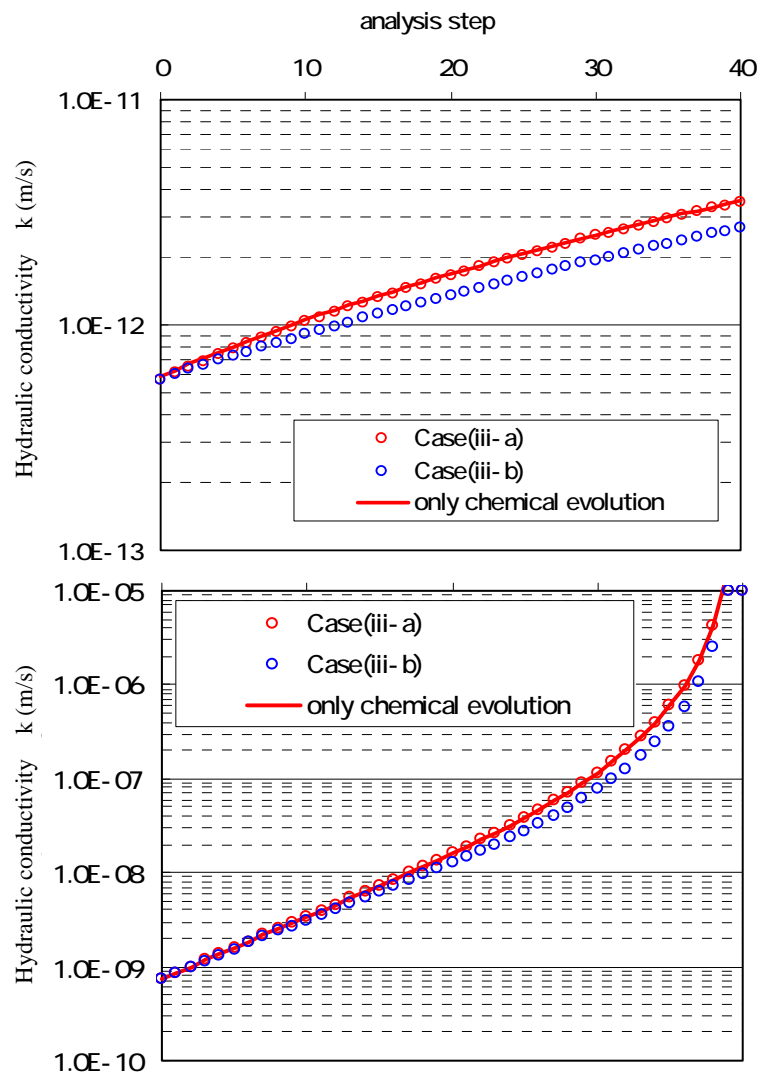

Fig.5 Alteration of hydraulic conductivity

(Top graph : bentonite, Bottom graph : cement-based materials)

\section{CONCLUSION}

The long-term deformation of the saturated engineered barrier is analyzed by using MACBECE.

Assuming 4 different chemical alteration scenarios with hard rock and soft creeping rock, a series of analytical case studies was performed. In hard host rock cases, where creep deformation can be ignored, tunnel deformation by swelling pressure of the buffer material is insignificant and the buffer material seems to remain intact. On the other hand, for the cases with creeping host rock, buffer material is compacted to some extent (i.e., thickness of the buffer material under the waste emplacement area reduced $5 \mathrm{~cm}$ ).

It should be noted that creep deformation is expected to be around several $\mathrm{cm}$ in a soft rock site with ordinal strength $\left(q_{u}=15 \mathrm{MPa}\right)$ and thickness reduction of the buffer material will be smaller than $5 \mathrm{~cm}$. In the repository, $120 \mathrm{~cm}$ of thickness of the buffer was designed (JAEA and FEPC, 2007). This reduction dose not affected the safety assessment, because the required thickness of buffer is $1.0 \mathrm{~m}$ for the safety assessment.

Moreover, since the buffer density is thought to be increased even if the buffer thickness is reduced several cm, which is favorable for preventing nuclide migration, the influence of the deformation in the near-field can be considered to be insignificant.

\section{REFERENCES}

Sahara, F., et al., 2006, "Development of a Mechanical Analysis System Considering Chemical Transitions of Barrier Materials”, WM'06, Tucson, Arizona

JAEA and FEPC, 2007, "Second Progress Report on Research and Development for TRU Waste Disposal in Japan -Repository Design, Safety Assessment and Means of Implementation in the Generic Phase-“, (in preparation) 
Metcalf, R. and Walker, C., 2004, "Proceedings of the International Workshop on Bentonite-Cement Interaction in Repository Environments”, NUMO-TR-04-05

Yokozeki, K. et al., 2002, "Analysis of Old Structures and Numerical Model for Degradation of Culcium Ion Leaching from Concrete”, Journal of Materials, Concrete and Structures and Pavements, No.697, V-54, pp.51-64. (in Japanese)

Yokozeki, K. et al., 2002, "Prediction of Changes in Physical Properties due to Leaching of Hydration Products from Concrete”, J. Advanced Concrete Technology, Vol.1, No.2, pp.161-171

Sekiguchi, H. and Ohta, H., 1977, "Induced anisotropy and time dependency in clays”, Proc. Socialty Session 9, 9th ICSMFE, Tokyo, pp.229-239.

Motojima, M. et al., 1981, "The Stability of Rock Foundation with Considering Strain-Softening Material”, CRIEPI 380036. (in Japanese)

Ito, H. and Mihara, M., 2005, “A Study on Changes in Hydraulic Conductivity of Saturated Bentonite-based Materials”, JNC TN8400 2005-029 (in Japanese)

Mihara, M. et al., 2003, "A study on evolution of long-term hydraulic condition in near-field for TRU waste disposal system (6)", 2003 Fall Meeting of the Atomic Energy Society of Japan, III, p.580. (in Japanese) 